\title{
DESIGN AND SIMULATION OF BOOST CONVERTERS SUITABLE FOR PHOTO VOLTAIC APPLICATIONS
}

\author{
Madhusudhana $\mathbf{J}^{1}$, P S Puttaswamy ${ }^{2}$, Mohamed Rafiq A Chapparband ${ }^{3}$ \\ ${ }^{I}$ Department of Electrical Engineering, UVCE, Bengaluru \\ ${ }^{2}$ Department of Electrical Electronics Engineering, PESCE \\ ${ }^{3}$ Department of Electrical Engineering, UVCE, Bengaluru
}

\begin{abstract}
The main purpose of this paper is to design $d c$ - $d c$ boost converters which are required for a multi-level inverter circuit, to boost the output voltage of photovoltaic module to a suitable value. The output voltage of photo voltaic module is low and also fluctuating in nature. A boost converter is required to get a higher and stabilized dc output voltage. In this paper three voltage fed-back boost converters are designed and modelled using state space averaging technique (SSA). The output of the converter is measured and compared with a reference voltage to generate an error signal which is used to vary the duty cycle of the pulse width modulated signal from the controller with the help of SSA technique. The Simulation studies has been carried out for both open loop and closed loop with the circuits operating in continuous conduction mode with 27V, 54V, 78V output voltages, by considering $12 \mathrm{~V}$ input voltage and $100 \mathrm{kHz}$ switching frequency using matlab/Simulink software. The simulation results establish that the proposed design is capable to produce constant output voltages for variable input voltage and variable load.
\end{abstract}

Keywords: DC/DC Boost Converter, State Space Averaging, Photo Voltaic Module, PID Controller.

\section{INTRODUCTION}

In recent years, dc-dc converters are widely used in switched mode power supplies. These converters are power electronic circuits that convert one level dc voltage to a different dc voltage level, often providing a regulated output. There are various dc-dc converter topologies such as buck, boost, buck-boost, Cuk converter etc. Of these different converters, only the buck and boost are the basic converter topologies. The other converters are derived from these two basic converter topologies. Each converter topology has its own principle of operation, advantages and disadvantages.

A boost converter is used to step up unregulated dc output voltage of a PV module to a higher constant output voltage that is required for multi-level inverter circuits. The design and development of boost converter is mainly concern of its efficiency, output power and ease of design. The photovoltaic module uses boost converter as a medium to produce the desired power required for successful operation of Multilevel inverter, which in turn converts the signal to $\mathrm{AC}$ and passes to the load. The schematic operation of power transmission is represented in Figure 1.1

Figure 1.1 depicts boost converter. The operation of the boost converter is mainly controlled by the $\mathrm{ON}$ and $\mathrm{OFF}$ duration of the switch. Adjusting the ON and OFF duration of the switch at constant switching frequency is called pulse width modulation switching. The switching duty cycle $d$, is defined as the ratio of $O N$ duration to the switching time period. Based on the energy absorbed and transferred by the inductor in the converter, the converter is said to operate in two different modes known as continuous and discontinuous conduction mode. In discontinuous conduction mode, the current in the inductor is discontinuous which in turn indicates that there is interruption of power transmission to the load, due to which the stress on the load increases. Hence, the boost converters are operated in continuous conduction mode for better regulation, continuous power transmission and reliability of the system.

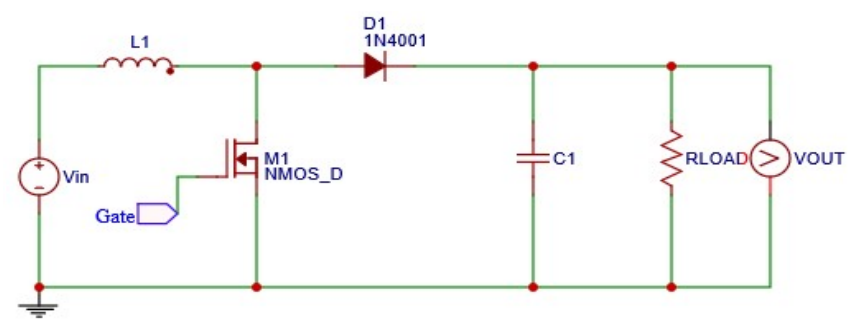

Fig 1.1: Schematic of boost converter

\section{ANALYSIS AND DESIGN OF BOOST CONVERTER IN CONTINUOUS CONDUCTION MODE}

The analysis is carried out by examining the inductor voltage and current over a period of time and also with the following assumptions: 
a. Steady state conditions exist,

b. The switching period is $\mathrm{T}$, and the switch is closed for time ton and open for $t_{\text {off, }}$

c. The inductor current is continuous,

d. The components used are ideal.

The switch M1 is turned on for a period $t_{o n}$ in boost converter as shown in figure 2.1. The input current flows through the inductor and switch M1. During this the energy gets stored in inductor for a period $t_{o n}$. When the switch M1 is turned off for a period $t_{\text {off }}$, the current that was flowing through the switch would now flow through inductor $L$, diode $D$, Capacitor $C$ and to the load $R$ as shown in figure 2.2. During $t_{\text {off }}$ period the stored energy in the inductor is released to the load and due to which the current through the inductor decreases until the switch is again turned on in the next cycle. Therefore, this results in an output voltage always greater than the input voltage.

The figure 2.3 shows the output voltage $V_{o}$ and inductor current $I_{L}$ waveforms for one period. The expression for output voltage is given by

$$
V o=\frac{1}{1-d} \operatorname{Vin}--------(1)
$$

Where $V_{o}$ is the output voltage, $d$ is duty cycle, and $V_{i n}$ is input voltage.

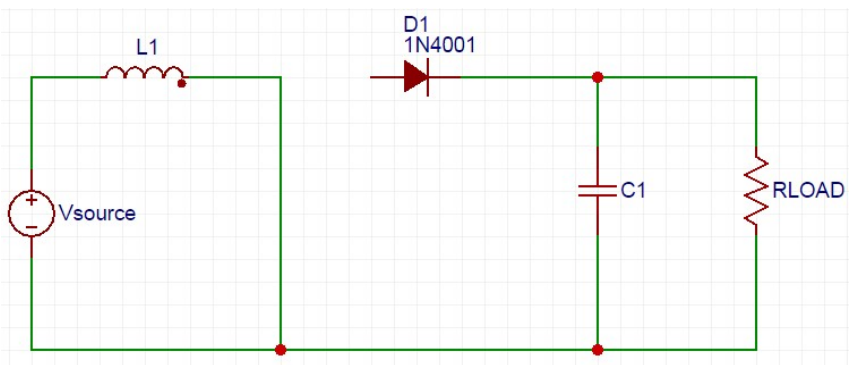

Fig 2.1, Circuit diagram of boost converter during $t_{\text {on }}$

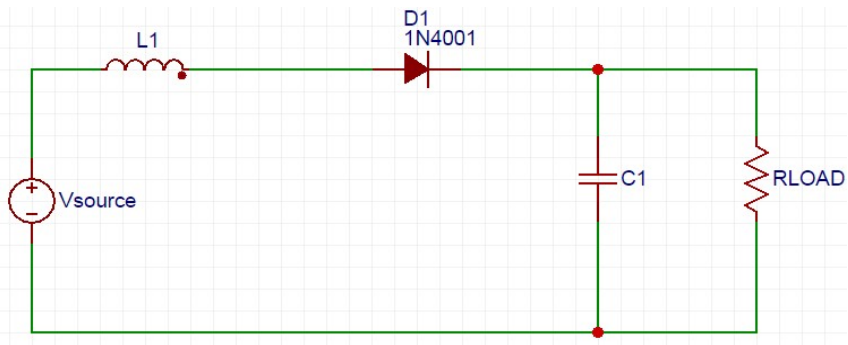

Fig 2.2, Circuit diagram of boost converter during $t_{\text {off }}$

In order to operate the converter in continuous conduction mode, the inductance is calculated such that the inductor current $I_{L}$ flows continuously and never fall to zero as shown in Figure 2.3. Thus, $L_{\text {min }}$ is given by

$$
L_{\min }=\frac{d(1-d)^{2}}{2 f} R--------(2)
$$

Where $L_{\text {min }}$ is the minimum inductance, $d$ is duty cycle, $R$ is output resistance, and $f$ is the switching frequency of switch M1. It is always advised to select the inductance value more than $L_{\text {min }}$, Hence, for practical purpose the inductance $L$ of the converter is considered to be with safety factor of 1.25 and is given by

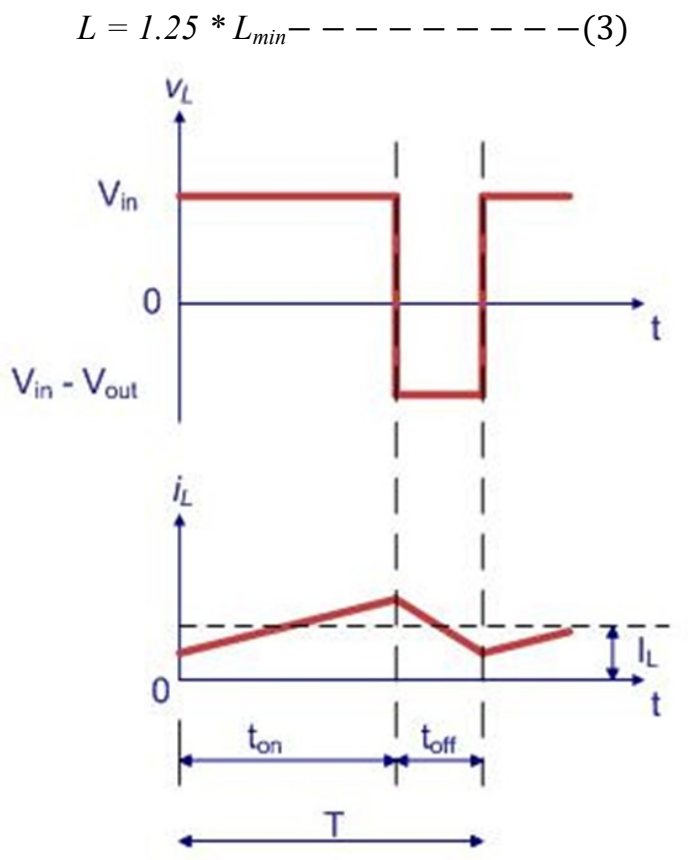

Fig 2.3.Boost converter waveforms under continuous conduction mode

The output capacitance to give the desired output voltage ripple is given by

$$
C_{\min }=\frac{d}{2 f V_{r}}--------(4)
$$

Where $C_{\text {min }}$ is the minimum capacitance, $d$ is duty cycle, $R$ is output resistance, $f$ is switching frequency of switch $M 1$, and $V_{r}$ is output voltage ripple factor. $V_{r}$ can be expressed as

$$
V_{r}=\frac{\Delta V o}{V o}--------(5)
$$

\subsection{Specifications}

The specification of the boost converters is considered based on the requirement of the output voltage for the 3 stage multilevel inverter, Figure 2.1.1 depicts that the 3 boost converters are connected to the individual $P V$ module and the converters are used to step up the unregulated voltage to a desired higher level voltage of $27 \mathrm{~V}, 54 \mathrm{~V}$ and $78 \mathrm{~V}$ as needed by the three $\mathrm{H}$ bridges Of the multi-level inverters [9] [10]. 


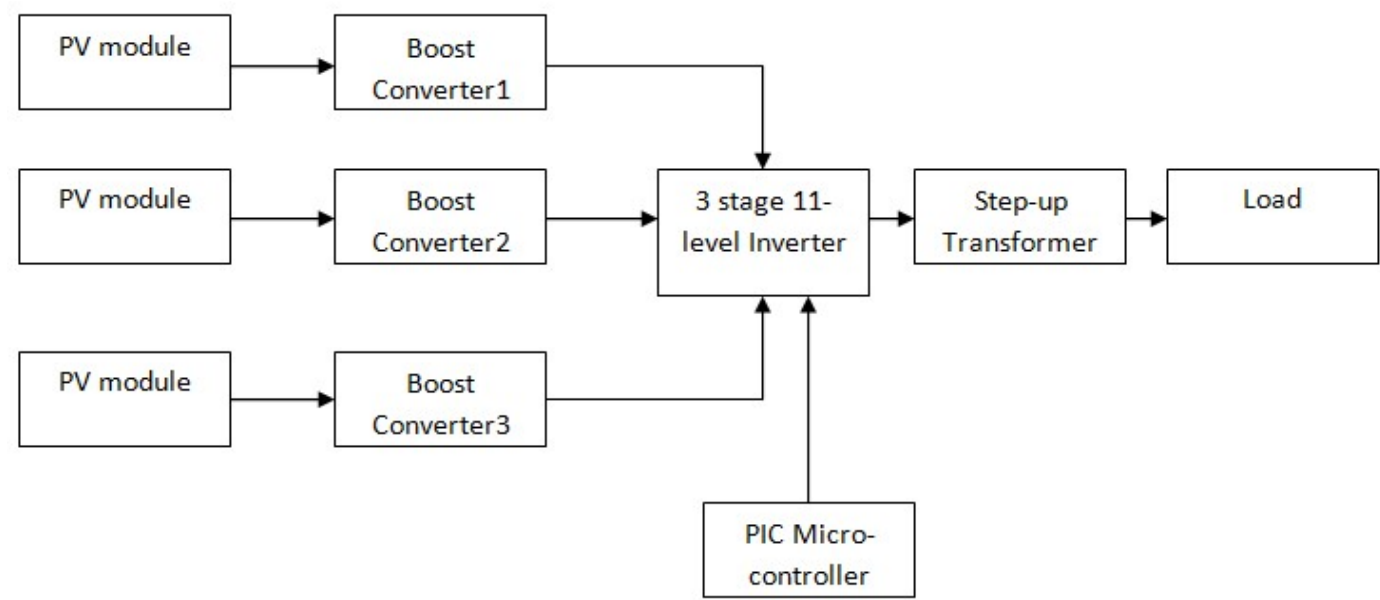

Fig 2.1.1 Block diagram of the power converter

The specifications considered for the boost converters are shown in table 1 .

Table 1: Specification of the Proposed Boost Converter

\begin{tabular}{|l|l|l|l|}
\multicolumn{1}{l}{$(\mathrm{BC})$} \\
\hline Mode & BC 1 & BC 2 & BC3 \\
\hline Output Voltage (Vo) & $27 \mathrm{v}$ & $54 \mathrm{v}$ & $78 \mathrm{v}$ \\
\hline Switching Frequency & $100 \mathrm{kHz}$ & \\
\hline Input Voltage (Vin) & $12 \mathrm{v}$ & \\
\hline RL Load & $20 \mathrm{Ohms}$ & \\
\hline Voltage Ripple & $1 \%$ \\
\hline
\end{tabular}

\subsection{Design of Inductor, Capacitor and IL Values}

\section{a. Selection of Inductor}

Equation (2) is the minimum inductance for boost converter to operate in continuous conduction mode, therefore the selection of the inductor should be higher than the calculated value in Equation (3).

\section{b. Selection of Output Capacitor}

Equation (4) gives the minimum capacitance for calculating ripple voltage. By fixing the voltage ripple to $1 \%$, the capacitance value is chosen.

a. Design for Boost Converter $\mathbf{1}\left(V_{\text {in }}=12 \mathrm{~V}, V_{\text {out }}=\right.$ 27V):

Duty Ratio: The desired duty cycle ratio is calculated as follows along with other required converter parameters

$\mathrm{D}=1-\frac{12}{27}=0.5555$

Inductor:

$L_{\text {min }}=\frac{d(1-d)^{2}}{2 f} R=\frac{0.55(1-0.55)^{2}}{2 * 100 * 10^{3}} * 20=11.1375 * 10^{-6} \mathrm{H}$

$\mathrm{L}=1.25 * L_{\min }=13.92 * 10^{-6} \mathrm{H}$

Capacitor:

$C_{\text {min }}=\frac{d}{2 f V r}=\frac{0.55}{2 * 100 * 0.1 * 10^{3}}=27.5^{*} 10^{-6} \mathrm{~F}$
Average Current $\left(I_{L}\right)$ :

$$
I_{L}=\frac{v_{S}}{R(1-d)^{2}}=\frac{12}{20(1-0.55)^{2}}=2.96 \text { Amps. }
$$

Similarly, by performing the similar calculation for the specifications provided for boost converter 2 and 3 we get the below values as shown in Table 2.2.1

Table2.2.1 Design values of Boost Converters

\begin{tabular}{|l|l|l|l|l|}
\hline $\begin{array}{l}\text { Boost } \\
\text { Converter }\end{array}$ & $\begin{array}{l}\text { Duty } \\
\text { Ratio }\end{array}$ & $\begin{array}{l}\text { Inductor(L) } \\
\text { in micro } \\
\text { Hendry }\end{array}$ & $\begin{array}{l}\text { Capacitor(C) } \\
\text { in micro } \\
\text { farad }\end{array}$ & $\begin{array}{l}\mathrm{I}_{\mathrm{L}} \text { in } \\
\text { Amps }\end{array}$ \\
\hline 1 & 0.555 & 13.92 & 27.5 & 2.96 \\
\hline 2 & 0.777 & 5.02 & 38.5 & 11.34 \\
\hline 3 & 0.846 & 9.10 & 42.0 & 23.43 \\
\hline
\end{tabular}

It is very essential to maintain constant output voltage due to variations of source voltage or load for better regulation purpose. The open loop system fails to achieve constant output for the variations of source voltage and load.In order to produce a constant output voltage, voltage feedback control system is used. In this control system, output voltage is measured and compared with a reference voltage and the differential value is used to produce a pulse width modulation signal. Any changes in the output voltage will lead to the changes of duty cycle in pulse width modulation signal.

Following techniques are widely used to model the DC-DC converters when the duty cycled is in the range $(0.5<\mathrm{d}$ $<1)$. [4]

1. State space Averaging technique (SSA)

2. Slope compensation

\subsection{State Space Averaging (SSA)}

The most widely used modelling method for PWM converters is SSA. It is a small signal modelling of the converter.There are 3 basic steps to be followed for SSA technique

1. Identify the switched models over one switching cycle

2. Identify the state variables of the converter 
3. Perform the state space averaging technique using the duty cycle as the weighing parameter and combine the state equations into a single averaged state equation.

The above three steps are carried out based on below assumptions.

Assumptions: 1) Components are ideal and lossless

2) Continuous conduction mode (CCM)

State variables: 1) Output voltage $\mathrm{v}_{\mathrm{o}}$

2) Inductor current $i_{1}$

3) Capacitor voltage $v_{c}$

4) Input voltage $v_{\text {in }}$

5) Duty cycle d

Due to ideal assumption, $V_{c}=V_{o}$. Therefore, one of the variable can be replaced by the other.

State equations for each interval of operation:

1. Switch $\mathrm{S}$ is turned $\mathrm{ON}$

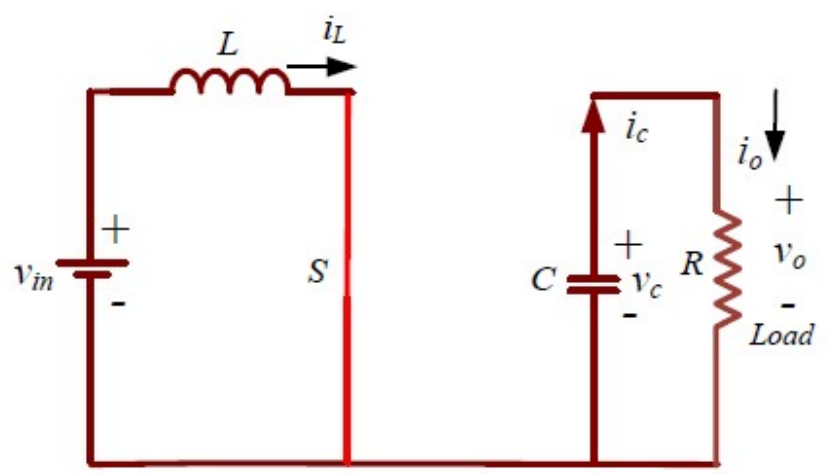

Fig 2.3.1 Switch is ON

$$
L \frac{d i_{l}}{d t}=v_{i n} \quad ; \quad C \frac{d v_{c}}{d t}=-\frac{v_{o}}{R}
$$

2. Switch $\mathrm{S}$ is turned $\mathrm{OFF}$

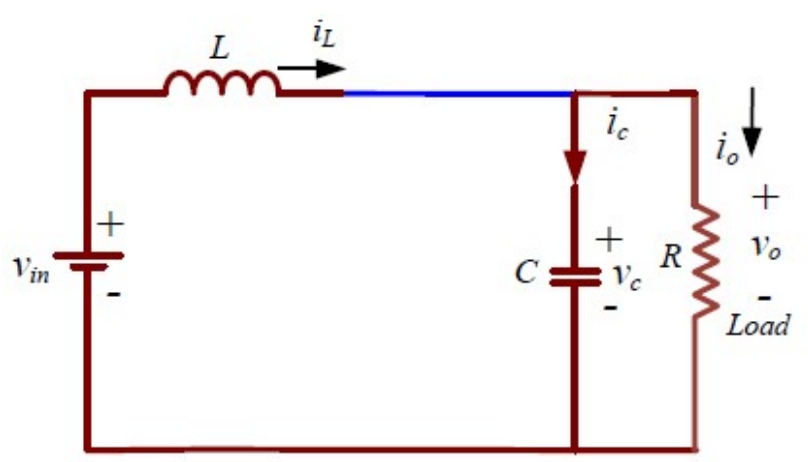

Fig 2.3.2 Switch is OFF

$$
L \frac{d i_{l}}{d t}=v_{i n}-v_{0} \quad ; \quad C \frac{d v_{o}}{d t}=i_{l}-\frac{v_{o}}{R}
$$

Averaging state equations over a switching cycle:

$$
L \frac{d i_{l}}{d t}=v_{i n}-(1-d) v_{0}
$$

$$
C \frac{d v_{o}}{d t}=(1-d) i_{l}-\frac{v_{o}}{R}
$$

Introducing perturbation in state variables such that-

$$
\begin{gathered}
i_{l}=I_{L}+\tilde{\imath}_{l}, v_{i n}=V_{\text {in }}+\tilde{v}_{i n}, v_{0}=V_{o}+\tilde{v}_{o}, d=D+\tilde{d} \\
L \frac{d\left(I_{L}+i_{l}\right)}{d t}=V_{\text {in }}+\hat{v}_{\text {in }}-(1-D-\tilde{d}) v_{0} \\
C \frac{d\left(V_{o}+\tilde{v}_{o}\right)}{d t}=(1-D-\tilde{d})\left(I_{L}+\tilde{\imath}_{l}\right)-\frac{V_{o}+\tilde{v}_{o}}{R}
\end{gathered}
$$

Equate ac and dc quantities and proceed with ac equations (neglect second order ac quantities)

$$
\begin{aligned}
& L \frac{d \tilde{\imath}_{l}}{d t}=\tilde{v}_{i n}-(1-D) \tilde{v}_{o}+V_{o} \cdot \tilde{d} \\
& C \frac{d \tilde{v}_{o}}{d t}=(1-D) \tilde{l}_{L}-I_{L} \tilde{d}-\frac{\tilde{v}_{o}}{R}
\end{aligned}
$$

Take Laplace transform

$$
\begin{aligned}
& \operatorname{sL} \tilde{\imath}_{L}(\mathrm{~s})=\tilde{v}_{i n}(s)-(1-D) \tilde{v}_{o}(s)+V_{o} \tilde{d}(s) \\
& \operatorname{sC} \tilde{v}_{o}(s)=(1-D) \tilde{l}_{L}(s)-I_{L} \tilde{d}(s)-\frac{\tilde{v}_{o}(s)}{R}
\end{aligned}
$$

Or

$$
\left(\mathrm{sC}+\frac{1}{R}\right) \tilde{v}_{o}(s)=(1-D) \tilde{l}_{L}(s)-I_{L} \tilde{d}(s)
$$

Prepare matrix-Small signal model:

Arranging in symmetrical sequence:

$\operatorname{sL} \tilde{l}_{L}(\mathrm{~s})+(1-D) \tilde{v}_{o}(s)=\tilde{v}_{i n}(s)+V_{o} \tilde{d}(s)$

$(1-D) \tilde{l}_{L}(s)-\left(\mathrm{sC}+\frac{1}{R}\right) \tilde{v}_{o}(s)=I_{L} \tilde{d}(s)$

In matrix form:

$$
\begin{aligned}
& {\left[\begin{array}{cc}
s L & 1-D \\
1-D & -\left(s C+\frac{1}{R}\right)
\end{array}\right]\left[\begin{array}{c}
\tilde{\imath}_{L}(s) \\
\tilde{v}_{o}(s)
\end{array}\right]=\left[\begin{array}{c}
V_{o} \\
I_{L}
\end{array}\right] \tilde{d}(s)+\left[\begin{array}{l}
1 \\
0
\end{array}\right] \tilde{v}_{i n}(s) } \\
& {\left[\begin{array}{c}
\tilde{\imath}_{L}(s) \\
\tilde{v}_{o}(s)
\end{array}\right]=} {\left[\begin{array}{cc}
s L & 1-D \\
1-D & -\left(s C+\frac{1}{R}\right)
\end{array}\right]^{-1}\left[\begin{array}{c}
V_{o} \\
I_{L}
\end{array}\right] \tilde{d}(s) } \\
&+ {\left[\begin{array}{cc}
s L & 1-D \\
1-D & -\left(s C+\frac{1}{R}\right)
\end{array}\right]^{-1}\left[\begin{array}{l}
1 \\
0
\end{array}\right] \tilde{v}_{i n}(s) }
\end{aligned}
$$

Inverse matrix can be calculated and the converter transfer functions can be obtained by solving matrix simply. 


\section{Control-to-output transfer function}

$$
\frac{\hat{v}_{o}(s)}{\hat{d}(s)}=\frac{(1-D) V_{o}-\left(L I_{L}\right) s}{(\mathrm{LC}) \mathrm{s}^{2}+\frac{\mathrm{L}}{\mathrm{R}} \mathrm{s}+(1-\mathrm{D})^{2}}
$$

After getting the transfer function of the converter, the calculated values of inductor and capacitor from the above design, specification values from table 2 for all the three boost converters are substituted in the transfer function. The obtained transfer function for each boost converter is fed into the SISO design tool command in the MATLAB/Simulinkin order to analyze the type of compensator required for the system by adding real pole or real zero in order to make the system stable. The obtained gain values as shown in Table 2.2.2

Table 2.2.2 $K_{p}, K_{i}, K_{d}$ Using PID tuning in Matlab SISO tool Command

\begin{tabular}{|l|l|l|l|}
\hline & $\begin{array}{l}\text { Boost } \\
\text { converter 1 }\end{array}$ & $\begin{array}{l}\text { Boost } \\
\text { converter 2 }\end{array}$ & $\begin{array}{l}\text { Boost } \\
\text { converter 3 }\end{array}$ \\
\hline $\mathrm{K}_{\mathrm{p}}$ & 0 & 0 & 0 \\
\hline $\mathrm{K}_{\mathrm{i}}$ & 11.76 & 3.22396 & 1 \\
\hline $\mathrm{K}_{\mathrm{d}}$ & 0 & 0 & 0 \\
\hline
\end{tabular}

From the Gain values obtained in Table 2, the feedback controller design for the Boost converter is carried out.

\section{Design of Closed Loop Boost Converter}

The feedback controller design is carried out from the gain values obtained from the simulated results. The controller circuit consists of Voltage divider network, "Differential Amplifier (Error Amplifier)" and Integral Amplifier.

a. Voltage Divider Circuit:The Voltage divider circuit shown in Figure 3.1.1, at the load is used to get the desired voltage level for the input of the Differential amplifier.

$$
V_{t}=\frac{V_{\text {out }} R_{2}}{R_{2}+R_{1}}
$$

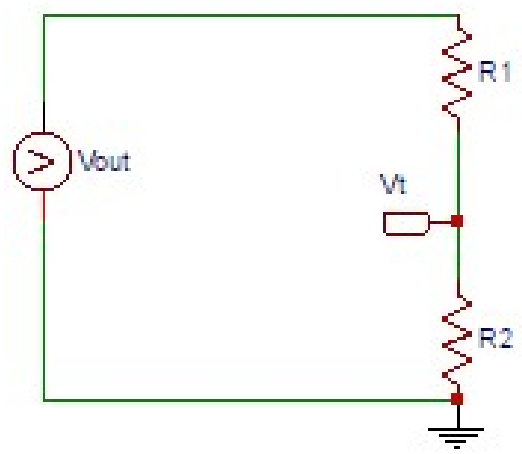

Fig 3.1.1 Voltage Divider

b. Differential Amplifier (Error-Amp):By connecting one voltage signal to one input terminal and another voltage signal to the other input terminal the resultant output voltage will be proportional to the "Difference" between the two input signals of $V_{i n}$ and $V_{r e f}$ and this type of circuit shown in Figure 3.1.2, can be used as a Subtracter and commonly known as a Differential Amplifier.

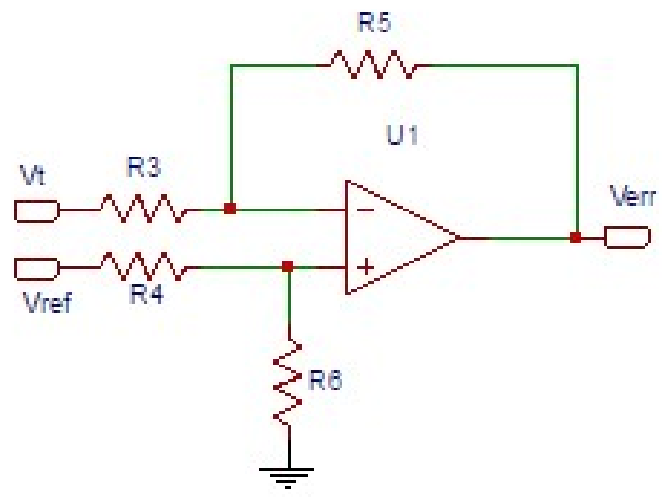

Fig 3.1.2 Differentiator

The transfer function for a Differential Amplifier circuit is given as:

$$
V_{\text {err }}=-\frac{R_{5}}{R_{3}} V_{t}+\left[1+\frac{R_{5}}{R_{3}}\right]\left[\frac{R_{6}}{R_{4}+R_{6}}\right] V_{\text {ref }}
$$

When $R 3=R 4$ and $R 5=R 6$ the transfer function formula can be modified to the following:

$$
V_{\text {err }}=\frac{R_{5}}{R_{1}}\left(V_{\text {ref }}-V_{t}\right)
$$

c. Integral Amplifier:If the purely Resistive $\left(\mathrm{R}_{\mathrm{f}}\right)$ feedback element of an inverting amplifier is changed to a Frequency dependent Impedance (such as a Capacitor, C), an RC Network across the operational amplifier known as integrator.

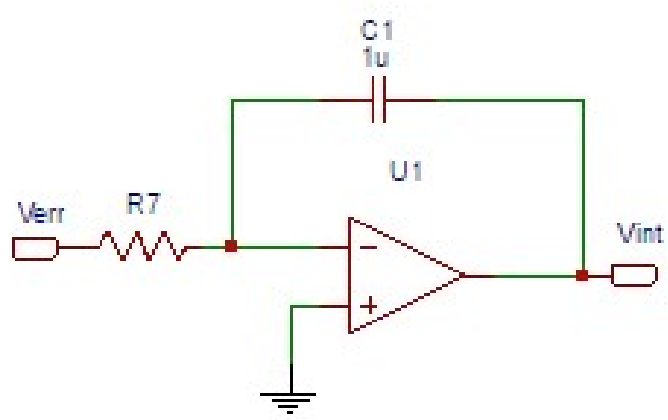

Fig 3.1.3 Integral Amplifier

The transfer function for an integral Amplifier circuit shown in Figure 3.1.3, is given as:

$$
V_{\text {int }}=-\frac{1}{R_{7} C_{2}} V_{\text {err }}
$$


The gain $K i$ is given by

$$
K_{i}=\frac{V_{\text {int }}}{V_{\text {err }}}
$$

Knowing the value of $\mathrm{Ki}$ from Table 2 and Assuming the Value of R7, The value of $C_{2}$ can be calculated.

The differential amplifier subtracts the output voltage and the reference voltage and the error value is fed to the input of Integrator. The integrator amplifies the input signal and the output of the integrator is fed to the PWM. The Circuit diagram of the closed loop Boost converter is shown in the below figure 3.1.4

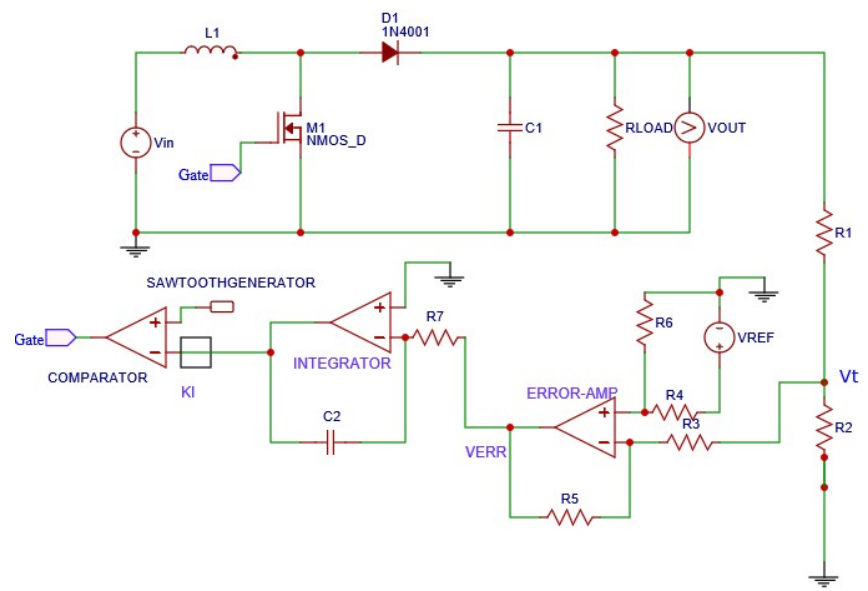

Fig 3.1.4, Circuit of Boost converter with Feedback

The control strategy for voltage feedback compares the output voltage with the desired value and the result is sent to the controller to generate the PWM signal required for switching device. If the error value is zero, then the PWM signal remains constant and if the error value is positive then the output voltage is greater than the desired voltage. Hence the controller reduces the duty cycle of the PWM signal. On the other hand, if the error value is negative then the output voltage is lesser than the desired voltage, then the controller increases the duty cycle of the PWM signal. Figure 3.1.5 shows the flow chart of the control strategy.

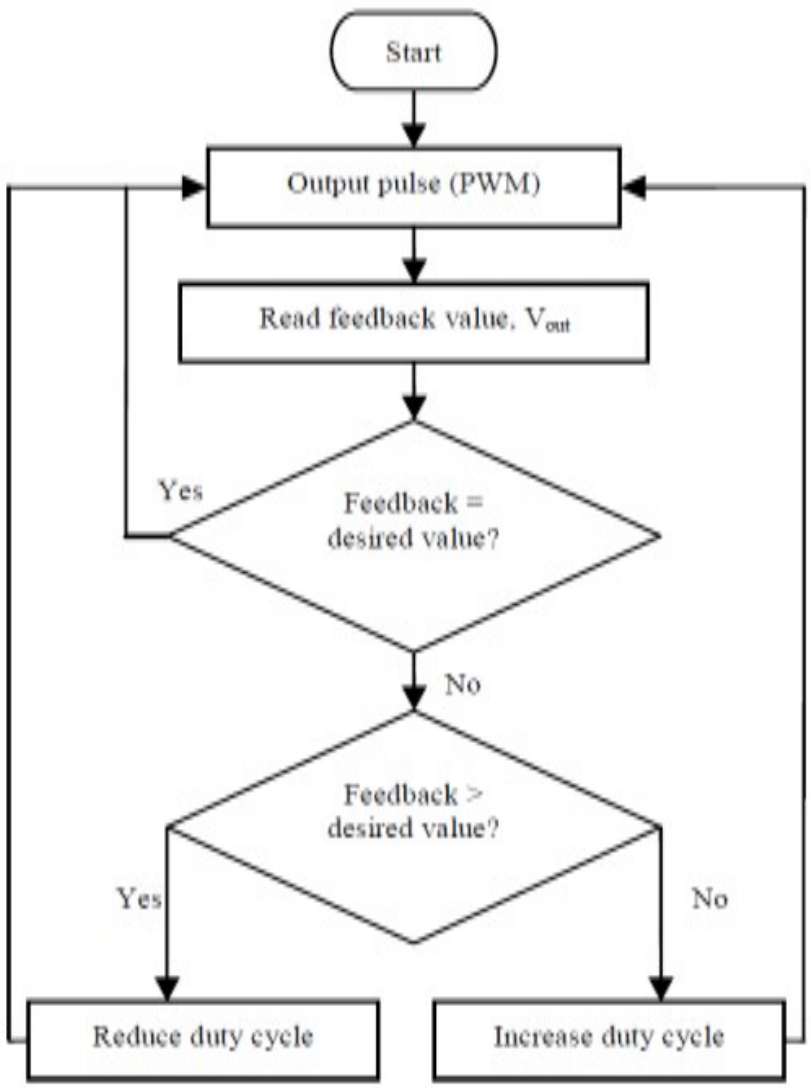

Fig 3.1.5, Control flow chart.

\section{SIMULATION CIRCUITS}

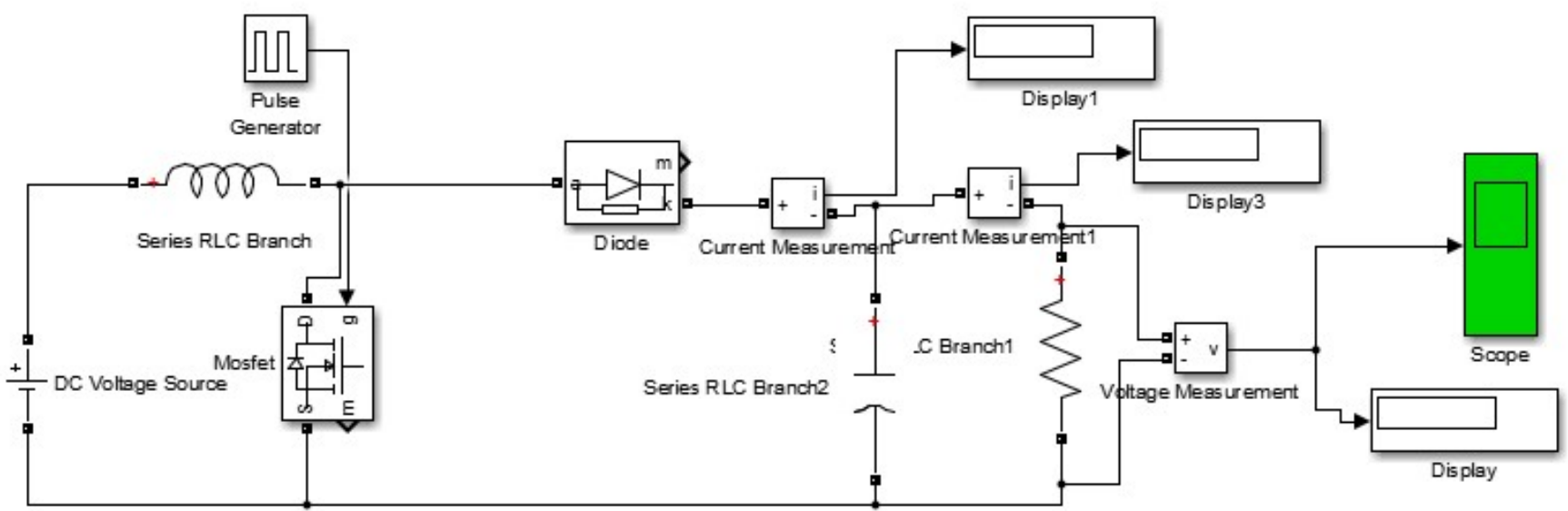

Fig 4.1, Boost Converter without feedback 


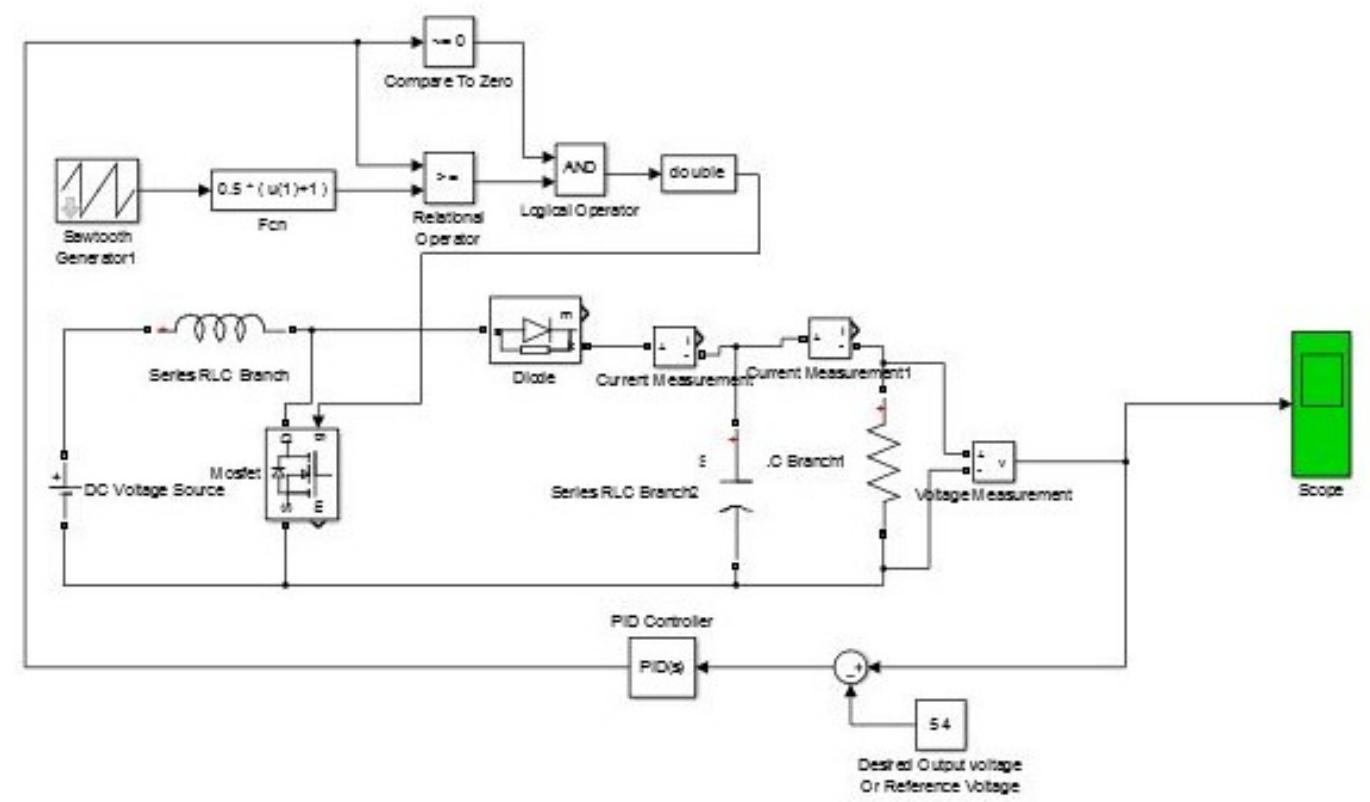

Fig 4.2, Boost Converter with feedback

The figure 4.1 represents the boost converter without feedback, with fixed input and load variable output voltage can be obtained by varying the duty ratio $d$ of the Mosfet. The boost converter without feedback is uncontrollable and lags to obtain constant output voltage for variable input source or variable load. In order to obtain a constant output voltage for variable input source or variable load, a feedback controller is designed and represented in the figure 4.2

\section{SIMULATION RESULTS}

Based on the proposed design, Matlab/simulink software is used to simulate the boost converter's performance. The simulation results of the boost converter with different values of input voltage and duty cycle are shown with respect to both mode of operation without feedback and with feedback.

\subsection{Open Loop (Without Feedback) Waveforms}

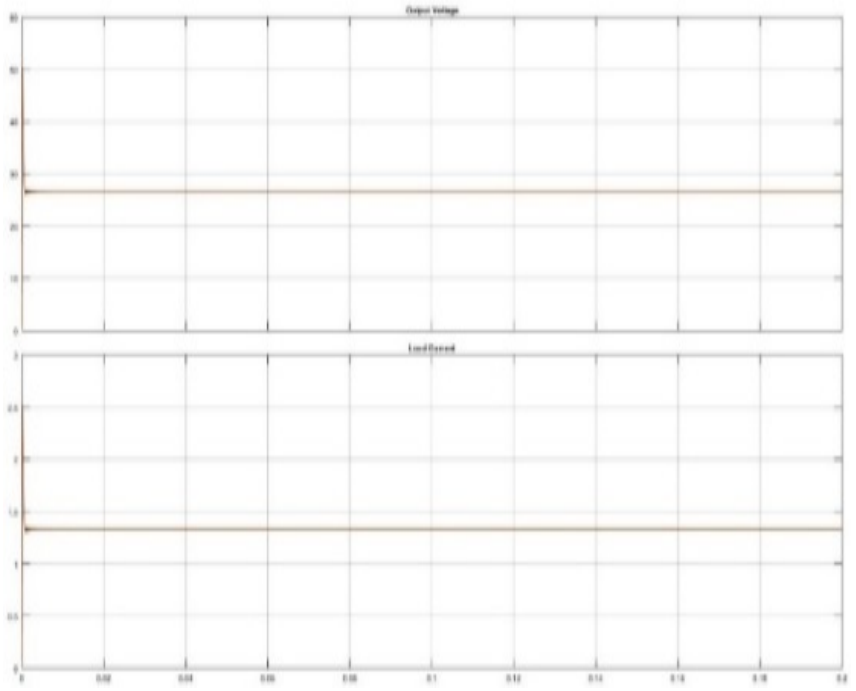

Fig 5.1, Boost converter waveform without feedback for duty cycle $\mathrm{d}=0.55 \mathrm{and} \mathrm{V}_{\text {out }}=27 \mathrm{v}$

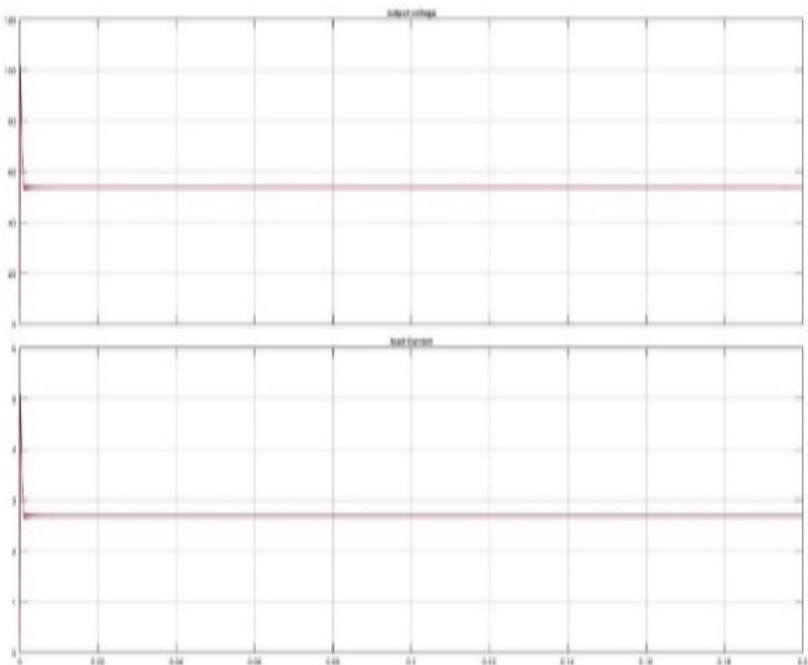

Fig 5.2, Boost converter waveform without feedback for duty cycle $\mathrm{d}=0.77$ and $\mathrm{V}_{\text {out }}=54 \mathrm{v}$
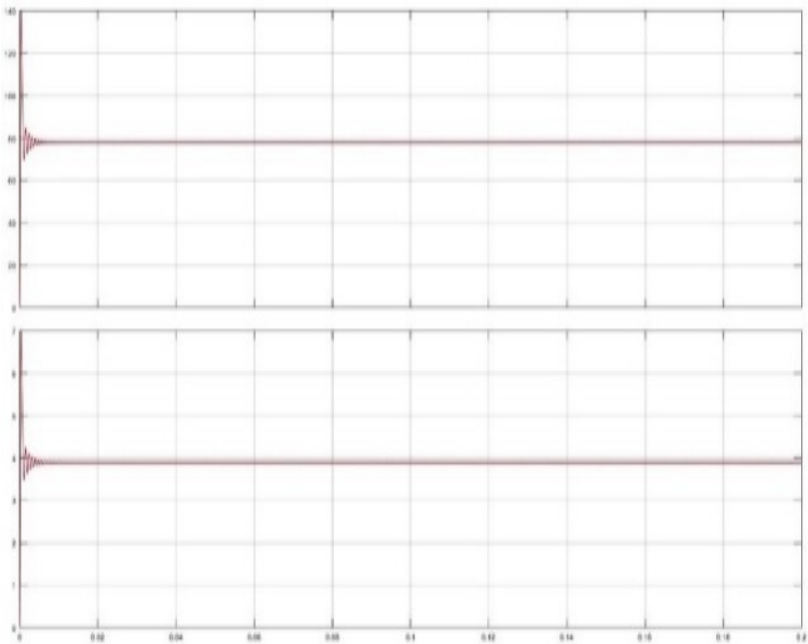

Fig 5.3, Boost converter waveform without feedback for duty cycle $\mathrm{d}=0.8416$ and $\mathrm{V}_{\text {out }}=78 \mathrm{v}$ 


\subsection{Closed Loop (With Feedback) Waveforms}

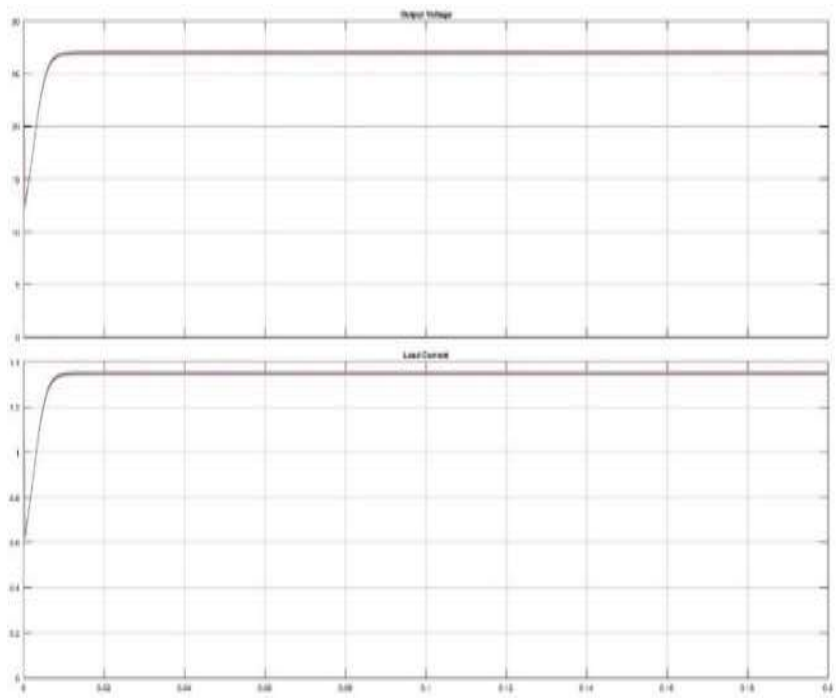

Fig 5.4, Boost converter waveform with feedback for output voltage $(27 \mathrm{~V})$, output current with $\mathrm{d}=0.55$.

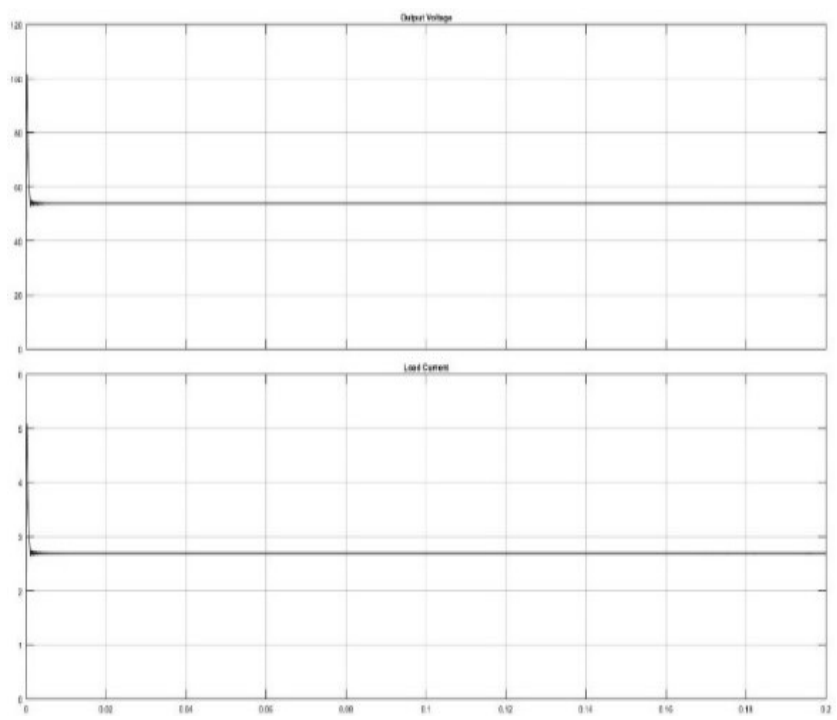

Fig 5.5, Boost converter waveform with feedback for output voltage $(54 \mathrm{~V})$, output currentwith $\mathrm{d}=0.77$.
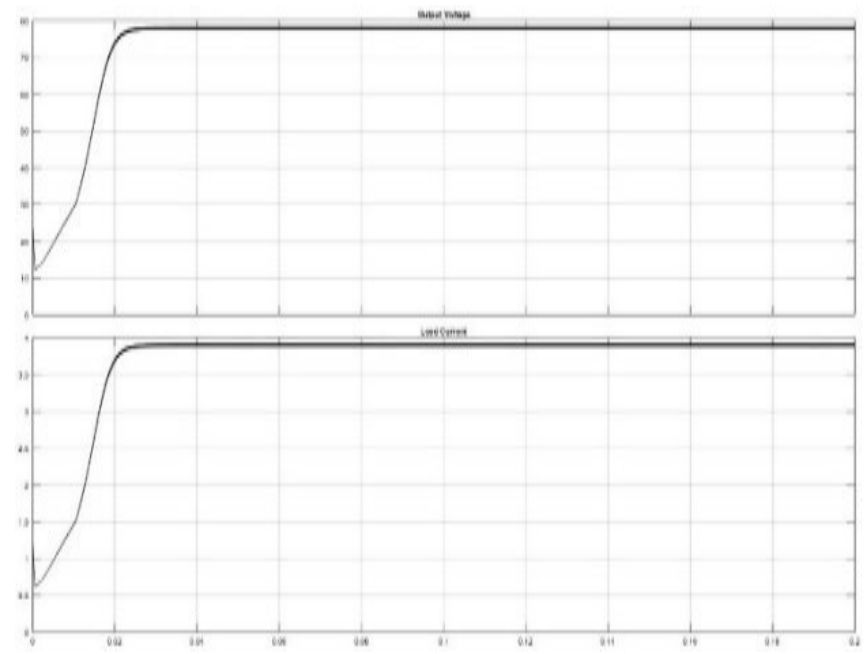

Fig 5.6, Boost converter waveform with feedbackfor output voltage $(78 \mathrm{~V})$, output current with $\mathrm{d}=0.8416$.
From the simulation results, the proposed converter is capable of providing a constant DC output voltage. The transient response does exists for a few milliseconds before settles to a steady state.

\subsection{Comparison of Results for Variation of Input} Voltage and Load With Respect To Open Loop and

\section{Closed Loop}

The simulated results are obtained for two boost converter with fixed and variable input voltage and also with fixed and variable load and are presented in the following section.

\section{a. Boost Converter $1(\mathrm{Vo}=\mathbf{2 7} \mathrm{V})$}

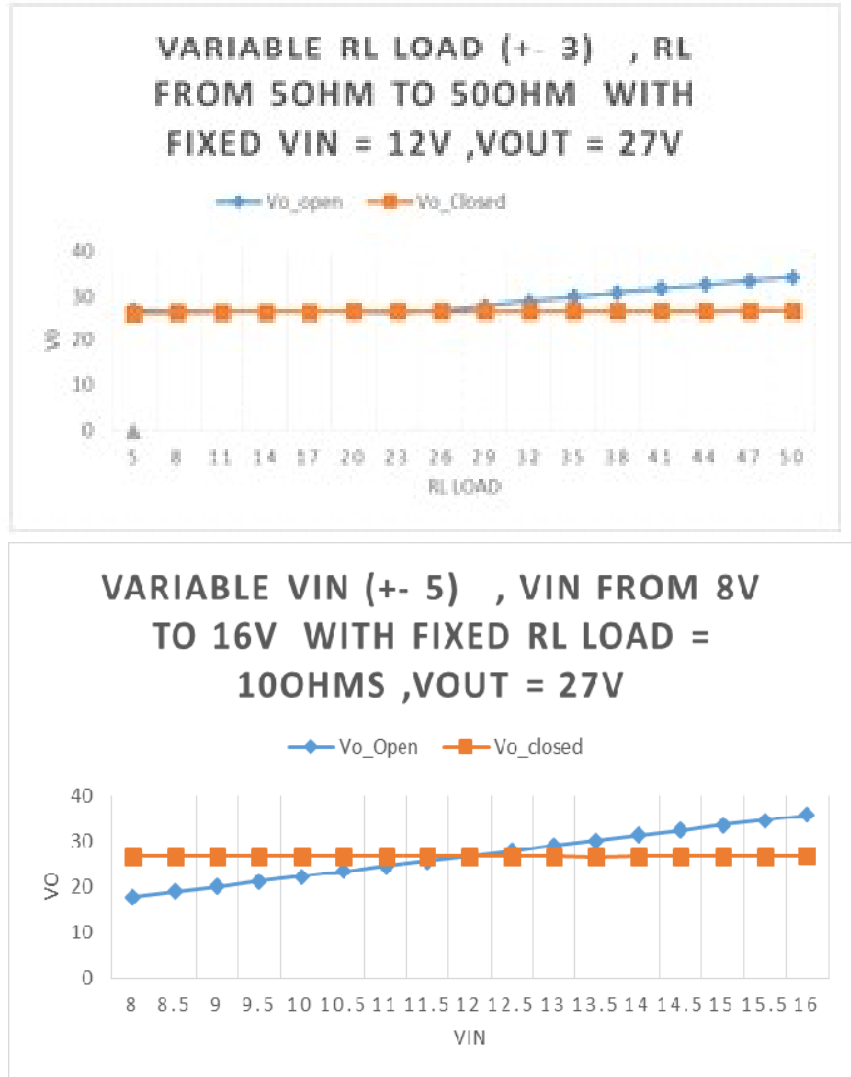

b. Boost Converter 2( $\mathrm{Vo}=54 \mathrm{~V})$
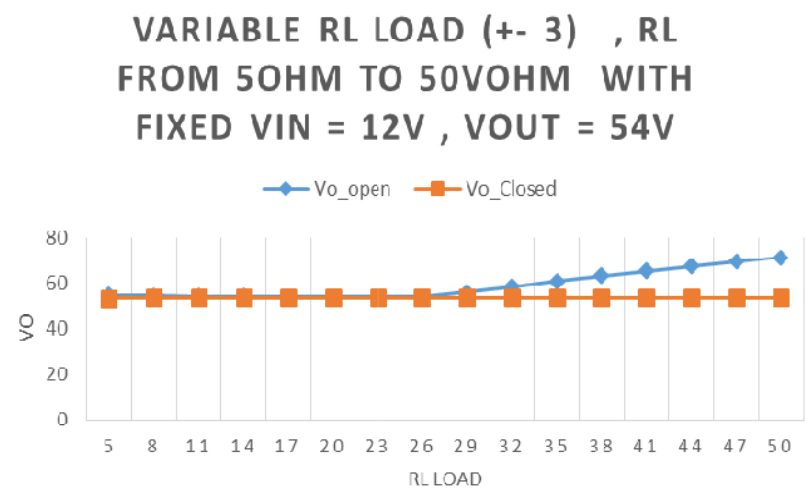

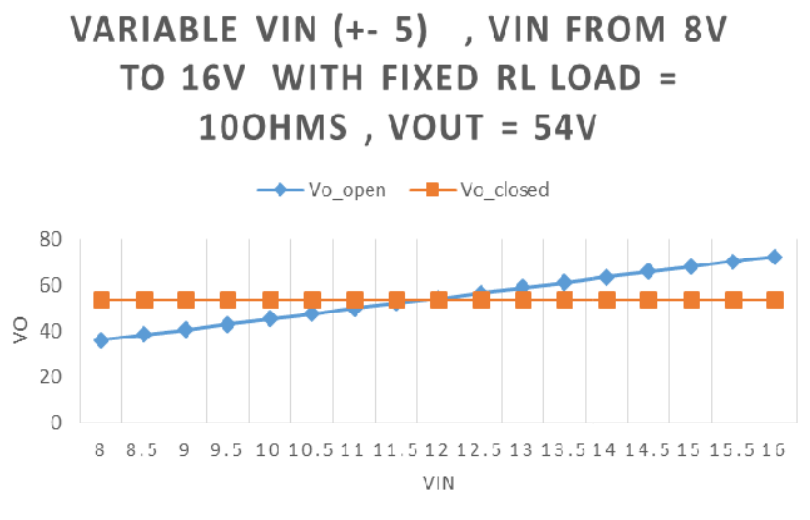

c. Boost Converter $3(\mathrm{Vo}=78 \mathrm{~V})$
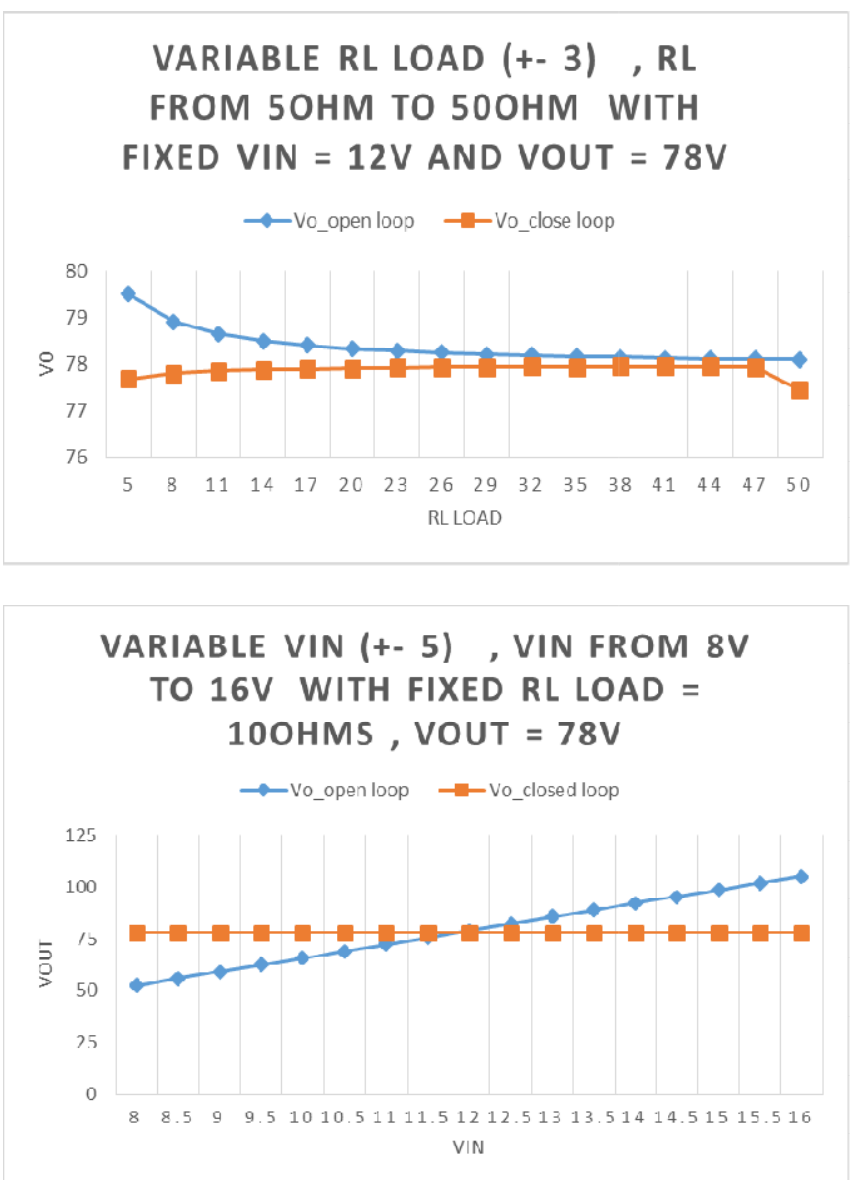

\section{CONCLUSION}

In this paper design and analysis of Boost converter as needed for integrating the PV module to multilevel inverter is carried out with and without feedback. The boost converter without feedback is unable to produce constant output voltage with either variable source or variable load. The above limitation scan overcome with the help of a closed loop Integral controller. The simulation studies carried out and the results obtained are compared with respect to closed loop and open loop. The results show that closed loop control produces better stabilized output voltages under different operating conditions than open loop control.

\section{REFERENCES}

[1]. M. ShanmugaPriya; R. Balasubramanian ," Analysis of multidevice interleaved boost converter for high power applications" Circuit, Power and Computing Technologies (ICCPCT), 2014 IEEE transaction

[2]. LopamudraMitra; Nibedita Swain, "Closed loop control of solar powered boost converter with PID controller"Power Electronics, Drives and Energy Systems (PEDES), 2014 IEEE International Conference

[3]. AbhisekMaiti; Kaushik Mukherjee; PrasidSyam,'Design, modeling and software implementation of a current-perturbed maximum power point tracking control in a DC-DC boost converter for gridconnected solar photovoltaic applications",2016 IEEE First International Conference on Control, Measurement and Instrumentation (CMI)

[4]. B. M. Hasaneen; Adel A. Elbaset Mohammed,'Design and simulation of DC/DC boost converter",Power System Conference, 2008. MEPCON 2008. 12th International Middle-East

[5]. Tasi-Fu Wu; Yu-Kai Chen ,Modeling PWM DC/DC converters out of basic converter units,1998 IEEE Transactions on Power Electronics

[6]. B. Bryant; M. K. Kazimierczuk,Open-loop powerstage transfer functions relevant to current-mode control of boost PWM converter operating in CCM,2005 IEEE Transactions on Circuits and Systems

[7]. M. F. N. Tajuddin; N. A. Rahim; I. Daut; B. Ismail; M. F. Mohammed,"State space averaging technique of power converter with digital PID controller",TENCON 2009 - 2009 IEEE Region 10 Conference

[8]. B. Bryant; M. K. Kazimierczuk,"Small-signal duty cycle to inductor current transfer function for boost PWM DC-DC converter in continuous conduction mode",Circuits and Systems, 2004. ISCAS '04. Proceedings of the 2004 International Symposium

[9]. Madhusudhana J, P S Puttaswamy, Harshit Agrawal "A comparative analysis of different multilevel inverters" International Journal of Advanced Research in Electrical, Electronics and Instrumentation Engineering(IJAREEIE) Vol. 5, Issue 7, July 2016 ISSN (Print): 2320 - 3765 ISSN (Online): $2278-8875$

[10]. Madhusudhana J, P S Puttaswamy, Sunil Kumar "Genetic algorithm based 15 level modified multilevel inverter for standalone photovoltaic applications", International Journal of Modern Trends in Engineering and Research (IJMTER) Volume 03, Issue 06, [June- 2016] ISSN (Online):2349-9745; ISSN (Print):2393-8161

[11]. Power Electronics and applications by L Umanand [12]. Power Electronics by Mohammad Rashid

[13]. M. Kanimozhi and Geetha, P., "A new boost switched capacitor multilevel inverter using different multi carrier PWM techniques", in 2014 International Conference on Circuits, Power and Computing Technologies, ICCPCT 2014, Noorul Islam UniversityNagercoil, Tamil Nadu; India, 2014

[14]. N. Mohan, W. P. Robbin, and T. Undeland; "Power Electronics: Converters, Applications, and Design" Segunda Edición, New York: Editorial: Wiley, 1995. 